\title{
Cognitive Function Profile of Post-Stroke Patients
}

\author{
Dila Larasati, ${ }^{1}$ Irma Ruslina Defi, ${ }^{2}$ Henny Anggraini Sadeli ${ }^{3}$ \\ ${ }^{1}$ Faculty of Medicine, Universitas Padjadjaran \\ ${ }^{2}$ Department of Physical Medicine and Rehabilitation, Faculty of Medicine, Universitas Padjadjaran-Dr. Hasan \\ Sadikin General Hospital, Bandung \\ ${ }^{3}$ Department of Neurology, Faculty of Medicine, Universitas Padjadjaran-Dr. Hasan Sadikin General Hospital, \\ Bandung
}

\begin{tabular}{|c|c|}
\hline \multirow[t]{3}{*}{ Abstract } & $\begin{array}{l}\text { Objective: To discover cognitive function profile of post-stroke patients } \\
\text { undergoing rehabilitation to inform rehabilitation professionals in planning } \\
\text { for a program and provide services that meet the patient's need. }\end{array}$ \\
\hline & $\begin{array}{l}\text { Methods: This study was a descriptive cross-sectional study involving } 32 \\
\text { post-stroke patients undergoing rehabilitation at the Physical Medicine } \\
\text { and Rehabilitation clinic of Dr. Hasan Sadikin General Hospital Bandung in } \\
\text { August-September 2014. An examination was conducted using the Mini } \\
\text { Mental State Examination (MMSE) to obtain the cognitive function profile of } \\
\text { post-stroke patients. }\end{array}$ \\
\hline & $\begin{array}{l}\text { Results: The results showed that almost all post-stroke patients undergoing } \\
\text { rehabilitation had normal cognitive functions }(93.8 \%) \text {, only few patients had } \\
\text { probable cognitive impairment }(6.2 \%) \text {. Probable cognitive impairment were } \\
\text { found in male and female patients who were in the age range of } 50-60 \text { years } \\
\text { who were elementary school graduates and in the sub acute phase of stroke. }\end{array}$ \\
\hline $\begin{array}{l}\text { Received: } \\
\text { January 10, } 2017\end{array}$ & $\begin{array}{l}\text { Conclusions: Almost all post-stroke patients undergoing rehabilitation have } \\
\text { normal cognitive functions, only minority of patients have probable cognitive }\end{array}$ \\
\hline $\begin{array}{l}\text { Revised: } \\
\text { February 15, } 2017\end{array}$ & impairment, and there are no patients with definite cognitive impairment. \\
\hline & Keywords: Cognitive function, education, rehabilitation, stroke \\
\hline March 6, 2017 & $\begin{array}{l}\text { pISSN: 2302-1381; eISSN: 2338-4506; http://doi.org/10.15850/ijihs.v5n1.962 } \\
\text { IJIHS. 2017;5(1):21-5 }\end{array}$ \\
\hline
\end{tabular}

\section{Introduction}

Stroke is known as one of the cerebral function abnormalities marked by a sudden decrease in neurological function due to cerebral blood circulation disturbance. Globally, stroke has become one of the main causes of disability in adults. Statistical data of the American Heart Association show that around 795.000 people experience stroke every year, with 610.000 cases of them are the first attack of stroke and 185.000 cases are recurrent attacks. ${ }^{1}$ Based on the Global Burden of Diseases, Injuries, and Risk Factors Study 2010, stroke is the third

\footnotetext{
Correspondence:

Dila Larasati, Faculty of Medicine, Universitas Padjadjaran-Dr. Hasan Sadikin General Hospital Jl. Raya Bandung-Sumedang KM 21 Jatinangor, Indonesia

e-mail: larasati.dila@gmail.com
}

leading cause of Disability Adjusted Life Years (DALYs) lost in the world. ${ }^{2}$

Impaired blood circulation to the brain may lead to tissue damage or death which then interrupts neurological functions, including the cognitive function which is regulated by the tissue. It is estimated that approximately 50\% of patients have cognitive impairment in the early phase after stroke and $32 \%$ of patients showed persistent cognitive impairment up to three years after the first attack of stroke. ${ }^{3}$ Typically, domains of cognitive function that are interrupted are attention, concentration, memory, and executive functions. ${ }^{4}$ Impaired cognitive functions may affect the ability of post-stroke patients to perform daily activities and also influence the recovery process. The patients with cognitive impairment require specific rehabilitation that is more difficult and time consuming. ${ }^{5}$ Hence, the assessment 
of cognitive function and the determination of cognitive status in post-stroke patients may provide information for rehabilitation professionals to plan the optimal rehabilitation program and provide services that meet the patient's needs. ${ }^{6,7}$

\section{Methods}

This study used a descriptive cross-sectional design and was performed at the Physical Medicine and Rehabilitation clinic of Dr. Hasan Sadikin General Hospital Bandung during the period of August-September 2014 and was approved by the hospital's Ethical Clearance Committee with the ethical clearance number LB.04.01/A05/EC/307/VII/2014.

The total sampling approach was applied for data collection with a minimum sample size of 82 patients based on the result of the calculation based on the sample size formula for descriptive study for categorical variables. It involved previously-diagnosed post-stroke patients who underwent rehabilitation for the first time in the clinic. There were only 32 posts-stroke patients who met the inclusion criteria, consisting of 20-60 years old poststroke patients who were in a conscious state and cooperative. The exclusion criteria were patients who probably have any cognitive impairment that was not caused by a stroke and aphasia patients.

The cognitive status of the subjects was decided based on an interview and observation of post-stroke patients using the Mini Mental State Examination (MMSE) ${ }^{8,9}$ It included the assessment of orientation of place and time, short and long-term memory, registration, recall, constructional ability, language, and the ability to understand and follow commands. The cognitive function was divided into three categories based on the MMSE score: normal (24-30), probable cognitive impairment (17-23), and definite cognitive impairment $(0-16)$. The cognitive function profile was obtained from a cross tabulation between the cognitive status and general characteristics of post-stroke patients (gender, age, level of education, and phase of stroke). The phase of stroke was divided into three categories based on the onset of stroke, which were categorized into acute phase $(<2$ weeks $)$, sub acute phase ( 2 weeks -6 months), and chronic phase ( $>6$ months). This study used descriptive statistics to analyzed data. The data was then processed using statistical computerized software.

\section{Results}

General characteristics of the post-stroke patients in the rehabilitation clinic are shown (Table 1). The number of male patients was higher than the female patients. Most of patients were in the age range of 50-60 years old. Based on the level of education, no patient did not attend school and most patients have graduated from elementary school.

Cognitive function profile of post-stroke patients in the rehabilitation clinic is portrayed (Table 2). In general, the post-stroke patients in this study had normal cognitive functions. Only few patients had probable cognitive impairments and no patient had definite cognitive impairment. The number of patients who had normal cognitive function was almost the same, while the number of patients with probable cognitive impairment consisted of 1 male and 1 female patients. Patients with probable cognitive impairment were in the age range of 50-60 years old, graduated from elementary school and were in the sub acute phase of stroke. More than a half of the patients were in the sub acute phase and there was no patientg in the acute phase. The number of patients who were in the sub acute phase was higher than patients in the chronic phase.

Table 1 General Profile of Post-Stroke Patients Based on Gender

\begin{tabular}{lccc}
\hline & \multicolumn{2}{c}{ Gender } & \\
\cline { 2 - 3 } & $\begin{array}{c}\text { Male } \\
\text { (n=18) }\end{array}$ & $\begin{array}{c}\text { Female } \\
\text { (n=14) }\end{array}$ & \\
\hline Age (year) & & & \\
$20-29$ & 0 & 0 & 0 \\
$30-39$ & 0 & 0 & 0 \\
$40-49$ & 4 & 4 & 8 \\
50-60 & 14 & 10 & 24 \\
Level of Education & & & \\
Not Attend School & 0 & 0 & 0 \\
Elementary School & 7 & 4 & 11 \\
Middle School & 1 & 6 & 7 \\
High School & 5 & 4 & 9 \\
University & 5 & 0 & 5 \\
Phase of Stroke & & & \\
Acute & 0 & 0 & 0 \\
Sub acute & 15 & 9 & 24 \\
Chronic & 3 & 5 & 8 \\
\hline
\end{tabular}


Dila Larasati, Irma Ruslina Defi, et al.

Table 2 Cognitive Function Profile of Post-Stroke Patients

\begin{tabular}{|c|c|c|c|c|}
\hline & \multicolumn{3}{|c|}{ Cognitive Function } & \multirow[b]{2}{*}{ Total } \\
\hline & $\begin{array}{l}\text { Normal } \\
(n=30)\end{array}$ & $\begin{array}{c}\text { Probable } \\
\text { Cognitive } \\
\text { Impairment } \\
(n=2)\end{array}$ & $\begin{array}{c}\text { Definite } \\
\text { Cognitive } \\
\text { Impairment } \\
(n=0)\end{array}$ & \\
\hline \multicolumn{5}{|l|}{ Age (year) } \\
\hline $20-29$ & 0 & 0 & 0 & 0 \\
\hline $30-39$ & 0 & 0 & 0 & 0 \\
\hline $40-49$ & 8 & 0 & 0 & 8 \\
\hline $50-60$ & 12 & 2 & 0 & 14 \\
\hline \multicolumn{5}{|l|}{ Gender } \\
\hline Male & 17 & 1 & 0 & 18 \\
\hline Female & 13 & 1 & 0 & 14 \\
\hline \multicolumn{5}{|l|}{ Level of Education } \\
\hline Not Attend School & 0 & 0 & 0 & 0 \\
\hline Elementary School & 9 & 2 & 0 & 11 \\
\hline Middle School & 7 & 0 & 0 & 7 \\
\hline High School & 9 & 0 & 0 & 9 \\
\hline University & 5 & 0 & 0 & 5 \\
\hline \multicolumn{5}{|l|}{ Phase of Stroke } \\
\hline Acute & 0 & 0 & 0 & 0 \\
\hline Sub acute & 22 & 2 & 0 & 24 \\
\hline Chronic & 8 & 0 & 0 & 8 \\
\hline
\end{tabular}

\section{Discussion}

Impaired cognitive function may affect the ability of post-stroke patients to perform their daily activities as well as influencing the recovery process. This study aimed to discover the cognitive function profile of post-stroke patients undergoing rehabilitation to provide information for rehabilitation professionals in order to plan the program and provide services including tools or human resources that can be involved in rehabilitation of post-stroke patients with or without cognitive impairment based on patient's characteristics.

The post-stroke patients in rehabilitation were mostly in the age range of 40-60 years old. This result was in accordance with data from the Centers for Disease Control and Prevention that showed that the prevalence of stroke increases with age. ${ }^{10}$

According to the Centers for Disease Control and Prevention, cognitive impairment did not occur only on one type of disease and was not limited to a specific age group. ${ }^{11}$ However, in this sudy, patients with probable cognitive impairment were in the age range of 50-60 years old.

The number of male patients was higher than female patients. This was in accordance with data from the Framingham Heart Study which stated that women aged 45-84 years had a lower risk of having a stroke compared to men, but this relationship reversed at older ages, with an increased risk of stroke in women aged over 85 years, making it higher that the risk for men. A study in Sweden also noted that the incidence of stroke in women is less than men at the age of 55-64 years, but at the age of 75-85 years, the incidence of stroke in women is higher than men. ${ }^{1}$

According to The Stroke Association, one of the cognitive impairments that can be caused 
by a stroke is vascular dementia, which is about $20 \%$ of all cases of dementia. ${ }^{12}$ More than a quarter of those who experienced a stroke suffered vascular dementia in three months. ${ }^{12}$ Cognitive impairment was more common in men because of the factors associated with a higher risk of stroke in men.

Based on the level of education, the results of this study indicated that patients with probable cognitive impairment were graduated from elementary school. Although there was no large number when compared with patients with normal cognitive function, this result was in accordance with research Centers for Disease Control and Prevention which stated that the prevalence of stroke is higher in adults with lower levels of education. ${ }^{10}$ Patients with higher level of education have a life style and risk factor profile that can prevent cognitive decline. $^{13}$

The frequency of cognitive impairment in the acute phase of stroke is estimated to be more than $70 \%$ but, in the first week and a few months after stroke, recovery of cognitive function occurs through the re-canalization followed by reperfusion or brain plasticity. ${ }^{14}$ The process of functional recovery in poststroke patients can still continue to occur up to a certain extent, especially in the first 3-6 months after a stroke or is in the sub acute phase of stroke rehabilitation. ${ }^{5}$ According to the results, most of the patients who come for rehabilitation were in the sub acute phase. Patients with probable cognitive impairment were also in the sub acute phase of stroke so cognitive impairment may turn to normal either during the rehabilitation or after it.

This study used MMSE as the instrument to obtain the cognitive profile for the reason that its administration is short and that it is was easy to use. The MMSE is as brief assessment tools particularly used in primary care and probably the most common way to do routine screening compared to other instruments. ${ }^{15}$ The MMSE is moderately sensitive $(0.66)$ to cognitive impairment but has a very good specificity (0.97) ${ }^{16}$

Limitation in this study is the number of samples did not meet the minimum number of samples required because the number of new patients in the clinic of Physical Medicine and Rehabilitation Dr. Hasan Sadikin General Hospital Bandung is relatively less compared with patients who have undergone treatment. This study was also limited by the minimum amount of time so that the required sample size could not be fulfilled. The results of this study cannot be generalied because this study only took post-stroke patients population undergoing rehabilitation at Dr. Hasan Sadikin General Hospital Bandung, so it cannot represent the whole population of Indonesia or the global population.

Based on these limitations, it is suggested that further research is carried out in a longer time to obtain a sufficient sample size to represent the general population. In addition, further research needs to be done regarding the location of the lesion in the brain so the appropriate rehabilitation program can be provided. Rehabilitation professionals is expected to provide services in accordance with the needs of patients, especially patients with probable cognitive impairment and patients who are in the sub acute phase of stroke. Appropriate rehabilitation programs like brain games are needed for patients with impaired cognitive function. Participation of patients and their families are also needed in the process of cognitive function and overall functional recovery.

It is concluded that the majority of the poststroke patients undergoing rehabilitation have normal cognitive functions (93.8\%) and only a small number of patients have probable cognitive impairment (6.2\%). No patient has been shown as having a definite cognitive impairment. Patients with probable cognitive impairment may associate with older age, lower educational level, and earlier phase of stroke.

\section{References}

1. Go AS, Mozaffarian D, Roger VL, Benjamin EJ, Berry JD, Blaha MJ, et al. Heart Disease and stroke statistics-2014 update: a report from the American Heart Association. Circulation. 2014;129(3):e28-292.

2. Murray CJL, Vos T, Lozano R, Naghavi M, Flaxman $\mathrm{AD}$, Michaud $\mathrm{C}$, et al. Disability-adjusted life

years (DALYs) for 291 diseases and injuries in 21 regions, 1990-2010: a systematic analysis for the Global Burden of Disease Study 2010. Lancet. 2012;380(9859):2197-223.

3. Pinter MM, Brainin M. Rehabilitation after stroke in older people. Maturitas. 2012;71(2):104-8. 
4. Hoffmann T, Bennett S, Koh C, McKenna K. A systematic review of cognitive interventions to improve functional ability in people who have cognitive impairment following stroke. Topics Stroke Rehabilitation. 2010;17(2):99-107.

5. Wirawan RP. Stroke rehabilitation in primary health care. Maj Kedokt Indon. 2009;59(2):6171.

6. Korner-Bitensky N, Barrett-Bernstein S, Bibas G, Poulin V. National survey of Canadian occupational therapists' assessment and treatment of cognitive impairment post-stroke. Aust Occup Ther J. 2011;58(4):241-50.

7. Gurr B, Ibbitson J. How does cognitive ability affect stroke rehabilitation outcomes? Int J Ther Rehabil. 2012;19(8):458-62.

8. Folstein MF, Folstein SE, McHugh PR. "Minimental state": a practical method for grading the cognitive state of patients for the clinician. J Psychiatric Res. 1975;12(3):189-98.

9. Folstein MF, Robins LN, Helzer JE. The minimental state examination. Arch General Psychiatry. 1983;40(7):812.

10. Centers for Disease Control and Prevention. Prevalence of stroke--United States, 20062010. MMWR. 2012;61(20):379-82.

11. Centers for Disease Control and Prevention. Cognitive impairment: a call for action, Now! 2011. [cited 2015 Jan 6]. Available from: https://www.cdc.gov/aging/pdf/cognitive_ impairment/cogimp_poilicy_final.

12. The Stroke Association. Cognitive Impairment After Stroke. 2010.

13. Khedr EM, Hamed SA, El-Shereef HK, Shawky OA, Mohamed KA, Awad EM, et al. Cognitive impairment after cerebrovascular stroke: Relationship to vascular risk factors. Neuropsychiatr Dis Treatment.
2009;5:(1):103-16.

14. Danovska M, Peychinska D. Post-stroke cognitive impairment-phenomenology and prognostic factors. Journal of IMAB-Annual Proceeding Scientific Papers. 2012;18(3):2907.

15. Cullen B, O'Neill B, Evans JJ, Coen RF, Lawlor BA. A review of screening tests for cognitive impairment. J Neurol Neurosurg Psychiatry. 2007;78(8):790-9.

16. Godefroy O, Fickl A, Roussel M, Auribault C, Bugnicourt JM, Lamy C, et al. Is the Montreal cognitive assessment superior to the Mini-mental state examination to detect poststroke cognitive impairment? a study with neuropsychological evaluation. Stroke. 2011;42(6):1712-6.

17. Cumming TB, Churilov L, Linden T, Bernhardt J. Montreal Cognitive Assessment and MiniMental State Examination are both valid cognitive tools in stroke. Acta Neurol Scand. 2013;128(2):122-9.

18. Pendlebury ST, Mariz J, Bull L, Mehta Z, Rothwell PM. Impact of different operational definitions on mild cognitive impairment rate and MMSE and MoCA performance in transient ischaemic attack and stroke. Cerebrovasc Dis. 2013;36(56):355-62.

19. Oudman E, Postma A, Van der Stigchel S, Appelhof B, Wijnia JW, Nijboer TC. The Montreal Cognitive Assessment (MoCA) is superior to the Mini Mental State Examination (MMSE) in detection of Korsakoff's syndrome. Clin Neuropsychol. 2014;28(7):1123-32.

20. Olazarán J, Hoyos-Alonso MC, del Ser T, Garrido Barral A, Conde-Sala JL, Bermejo-Pareja F, et al. Practical application of brief cognitive tests. Neurologia. 2016;31(3):183-94. 